\title{
Do nacionalismo à dependência
}

Luiz Carlos Bresser-Pereira

Ol: M QUADRO do pensamento brasileiro em meados do século XX; um dos mais conhecidos ensaios sobre a história intelectual do Brasil; uma celebração da escola de sociologia de São Paulo ou da "escola de Florestan Fernandes", como o autor a denomina; uma tentativa de discutir as matrizes das formas de pensamento do Brasil, como o próprio autor a define; uma obra polêmica como são todas as histórias intelectuais; um ensaio sobre a crise do nacionalismo e o surgimento da teoria da dependência - essas são algumas das definições possíveis de Ideologia da cultura brasileira (1933-1974) de Carlos Guilherme Mota cuja segunda edição é agora publicada pela Editora 34, reproduzindo sem alterações a primeira edição, incluindo o prefácio de Alfredo Bosi. ${ }^{1} \mathrm{O}$ autor apenas acrescentou uma breve apresentação onde aproveita para fazer os agradecimentos que faltaram à primeira edição.

O livro começa com a análise dos quatro grandes autores que, com obras abrangentes, "redescobrem" o Brasil nos anos 1930 - as duas primeiras publicadas em 1933, ano inicial do estudo de Carlos Guilherme: Casa grande e senzala, de Gilberto Freyre (1933), Evolução econômica do Brasil, de Caio Prado Jr. (1933), Raizes do Brasil, de Sérgio Buarque de Holanda (1936), e, em segundo plano, História econômica do Brasil, de Roberto Simonsen (1937). Os anos 1930 são um período decisivo da história do Brasil: o momento em que a revolução capitalista (industrial e nacional) ganha impulso, que um Estado moderno, ainda que autoritário, substitui o Estado oligárquico que existira até então e começa a ser construído, e também, após a Revolução de 1930, momento da definição da identidade do Brasil. Os dois grandes analistas dessa identidade - Silvio Romero e Oliveira Vianna - são anteriores ao período estudado, mas não são esquecidos. O segundo período, no imediato pós-guerra, é de João Cruz Costa e Alice Canabrava, os "primeiros frutos da Universidade de São Paulo”. Em seguida, ao lado da figura isolada de Raimundo Faoro (1957), da primeira edição de Os donos do poder, temos o grande momento do nacionalismo desenvolvimentista (1953-1958), no qual aparecem três grandes figuras do Iseb (Hélio Jaguaribe, Roland Corbisier e Nelson Werneck Sodré), Celso Furtado e o historiador José Honório Rodrigues, restando, porém, quase esquecidos, Alberto Guerreiro Ramos, Álvaro Vieira Pinto e Ignácio Rangel, também do Iseb. Finalmente, os anos 1960 e 1970 serão o momento privilegiado da escola de Sociologia da Universidade de São Paulo. Dessa, Fernando Azevedo foi uma espécie de patrono liberal; Florestan Fernandes, o chefe da escola; e Antonio Candido, Roberto Schwarz, Fernando Henrique Cardoso, Octavio Ianni, Alfredo Bosi e Dante Moreira Leite, seus principais membros, embora praticamente todos os demais sejam também mencionados.

Em seu prefácio da primeira edição, Alfredo Bosi já percebe que o tema central do livro é a crise do nacionalismo dos "descobridores", e particularmente do nacional-desenvolvimentismo do Iseb e de Celso Furtado, em face da crítica 
de que os últimos são objeto pela escola de São Paulo. O nacional-desenvolvimentismo nacionalista tinha sua sede no Rio de Janeiro, seu centro era o Iseb, e seu herói imperfeito era Getúlio Vargas. Seu objetivo principal era a industrialização, e seu opositor, o liberalismo retórico das oligarquias proprietárias de terra e comerciais que até então haviam dominado o Brasil. Com a Revolução de 1930 e, em seguida, em 1932, com a derrota dessa oligarquia, seu núcleo mais poderoso criará em São Paulo, em 1934, a USP. Surge assim uma alternativa liberal, patrocinada pela elite local, ao nacionalismo econômico então dominante. Conforme observa Bosi (p.39), "enquanto o nacionalismo vazava-se nos textos teóricos do ISEB e nas revistas de tendência esquerdista, à Universidade (bloqueada a simpatia por qualquer projeto nacional-popular) restava a reafirmação dos princípios liberais que tinham como referência central a Escola".

A referência à Escola ou à educação se devia à contribuição de Fernando Azevedo nessa área. A escola de sociologia de São Paulo, que nos anos 1950 começa a ser construída por Florestan Fernandes sob inspiração da missão francesa na USP, começa também liberal. Já no final dessa década, porém, começa a tender para a esquerda, ao mesmo tempo que - na busca da hegemonia intelectual - inicia sua crítica ao nacionalismo dominante no Rio de Janeiro. Uma crítica que terá como base o método científico na pesquisa sociológica. Enquanto no Rio de Janeiro, especialmente, os sociólogos continuavam a escrever grandes ensaios, a USP começa a produzir estudos sociológicos científicos: estudos sobre os negros, os índios, os pobres, os empresários, os sindicatos, a escravi- dão, a industrialização. No célebre debate entre Guerreiro Ramos e Florestan Fernandes, enquanto o primeiro acusa a escola de São Paulo de alienação, o segundo acusa seus críticos do Rio de Janeiro (e também do Recife onde estava Gilberto Freyre) de falta de rigor científico porque não realizaram a pesquisa de campo necessária. Na verdade, o que estava então ocorrendo era, nos termos de Bourdieu, "uma luta pelo monopólio da ciência legítima". Esse monopólio pertencia, nos anos 1950, ao Rio de Janeiro e a Recife; nos anos 1960 passará para São Paulo. Nesse momento, porém, a visão hegemônica não é mais a liberal, mas a marxista. Não o marxismo do Partido Comunista que, em seu congresso de 1958, aderira às ideias do Iseb sobre a necessidade de uma revolução burguesa antes de uma revolução socialista, mas o marxismo da teoria da dependência em que André Gunder Frank (1966), em seu trabalho fundador $O$ desenvolvimento do subdesenvolvimento, havia rejeitado a possibilidade de existência de uma burguesia nacional nos países subdesenvolvidos.

Carlos Guilherme Mota tem bem presente em seu livro esse embate. Percebe que o problema estava no nacionalismo que fora dominante até 1964, mas, a partir de então, perdera grande parte de sua legitimidade política na medida em que continuava a ser abraçado por empresários industriais e militares no quadro de um regime autoritário apoiado pelos Estados Unidos. Como o Brasil naquele momento já realizara sua revolução capitalista, não havia mais justificativa ou lógica para um regime dessa natureza. Segundo Carlos Guilherme membro da escola de sociologia de São Paulo -, "os diagnósticos sobre a histó- 
ria social do Brasil e sua dinâmica mereceram reparos profundos, realizados por analistas que procuravam tirar alguma lição dos desacertos da ideologia do desenvolvimentismo e da política populista que levaram à derrocada dos setores progressistas em 1964" (p.84). Entretanto, escrevendo apenas dez anos depois do golpe militar, e dentro de um dos atores do drama, a escola de São Paulo, o autor tem dificuldade de compreender tudo que está acontecendo. Compartilha com seus colegas de escola a convicção que aqueles "desacertos" - especialmente a proposta de aliança das esquerdas com a burguesia nacional - haviam sido uma causa da grande derrota das esquerdas em 1964. Percebe que, em lugar da crítica ao imperialismo externo que caracterizava o nacional-desenvolvimentismo, a ideia de dependência das elites locais estava no fulcro do problema.

$\mathrm{Na}$ verdade, o que houvera fora um ressentimento com a derrota política, e a busca dos seus culpados internos - uma busca que a escola de sociologia de São Paulo não teve dificuldade em fazer: era o Iseb e o Partido Comunista que, ao adotarem a tese da burguesia nacional, haviam enfraquecido as esquerdas. Esse sentimento está em toda parte, mas em nenhuma ele aparece mais claramente do que em $A$ revolução brasileira, de Caio Prado Jr. (1966) - um dos seus últimos livros no qual ele rompe com o Partido Comunista e compartilha as ideias do momento em São Paulo de que os males advinham da "invenção" da burguesia nacional que "nunca existira nem poderia existir", mesmo porque, contrariando fatos empíricos, afirma que os empresários industriais brasileiro não tinham origem na imigração, mas no café.

Carlos Guilherme dá-se conta tam- bém de que há um "impasse da dependência cultural" - que aliás atinge a produção científica na universidade -, mas não logra um diagnóstico mais sistemático do que estava acontecendo. Assinala, entretanto, no capítulo em que trata do tema, a observação de Ruth Cardoso naquele ano de que "a universidade perdeu o caráter de fator criador na cultura brasileira" (p.302). ${ }^{2}$ Ela se referia, provavelmente, às cassações de direitos e aposentadorias compulsórias que muitos professores haviam sofrido, mas o problema se agravara muito em razão da redução da universidade ao papel de escrever "papers" sobre problemas específicos em vez dos ensaios que eram necessários para se poder compreender o Brasil de uma forma ampla.

Os estudos empíricos são um subsídio essencial, mas não são o resultado principal do trabalho nas ciências sociais. Nos anos 1960 e 1970, porém, em sua luta contra seus concorrentes intelectuais, seu argumento era o da legitimidade exclusiva dos estudos baseados em pesquisas. Mas esses não tinham opções senão responder a determinadas visões ideológicas. Segundo Carlos Guilherme (p.303), "uma tendência parece clara: as monografias surgem rompidas com o alinhamento teórico dos autores progressistas-nacionais que produziram nos marcos do nacional-desenvolvimentismo, dados seja por Furtado, seja por Werneck Sodré, etc.”. A tese era a da ciência contra a ideologia, embora seus autores soubessem, por suas leituras de Marx, que essa contraposição não faz sentido. $\mathrm{Na}$ verdade, eram contra o nacionalismo que acusavam de "populista". Destoam dessa linha, porém, os trabalhos de três críticos literários que são também sociólogos: "Literatura de subdesenvolvimento", de 


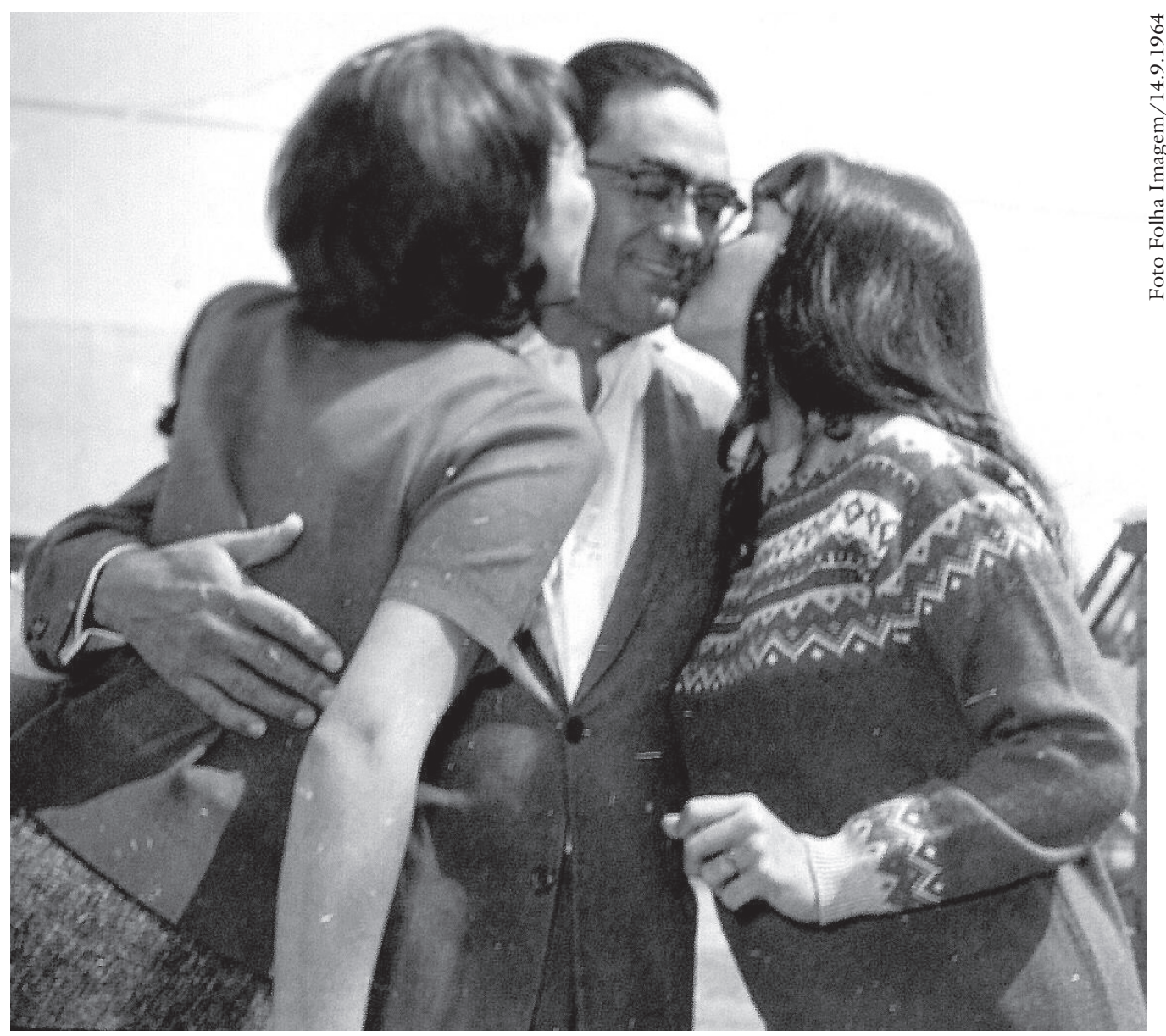

Florestan Fernandes é beijado por alunas, após ser libertado da prisão do Exército em 1964.

Antonio Candido (1973), "As idéias fora do lugar", de Roberto Schwarz (1973), e "Um testemunho do presente", o prefácio de Alfredo Bosi a Ideologia da cultura brasileira (1977) - três trabalhos que mostram que o nacionalismo não morrera em São Paulo, e - dada a coincidência de os três serem críticos literários - sugerem que o ofício das letras é menos repressivo do que o da sociologia. Antonio Candido, que será sempre a grande figura intelectual e humana do grupo, preocupa-se com a superação da dependência, que só poderá acontecer se houver "a capacidade de produzir obras de primeira ordem, influenciadas, não por modelos estrangeiros imediatos, mas por exemplos nacionais anteriores" (citado por Mota, p.318); Roberto Schwarz critica de forma incisiva as "ideias fora do lugar" - muito semelhantes às "ideias transplantadas" e ao "mimetismo cultural" a que se referiram com tanta frequência Oliveira Vianna e os intelectuais do Iseb; e Alfredo Bosi, no prefácio desse livro (p.44), referindose aos intelectuais dos anos 1970, afirma que eram semelhantes ao do final do século XIX, "pois o letrado colonizado tende a introjetar os valores da metrópole na forma por que esta os veicula".

Gilberto Freyre era um conservador, enquanto no tempo ainda dos Cadernos do Nosso Tempo (1952-1955) e nos três anos do Iseb estrito senso (1996-1998) seus intelectuais estavam filiados a tendências ideológicas variadas unificadas 
em torno do nacionalismo. O grupo só se inclinou fortemente para a esquerda na sua segunda e menos criativa fase, entre 1958 e 1964, quando foi extinto pelo golpe militar e os direitos de cidadania de vários de seus membros foram cassados. Já os representantes da escola de sociologia de São Paulo nos anos 1960, no quadro de uma grande mudança política internacional em direção à esquerda, estudam Marx, abandonam o liberalismo que dominara a USP nos seus primeiros anos e rumam em direção à esquerda e a uma posição antinacionalista, divergindo, nesse ponto, dos intelectuais do Partido Comunista. Na inclinação para a esquerda antinacionalista que se origina em São Paulo, porém, teremos duas vertentes. Conforme observa Carlos Guilherme Mota (p.288),

a intelectualidade mais progressista, vivendo o colapso do populismo, viuse obrigada a renunciar ao ideal mannheimiano de intelectual (sempre cima e à frente do processo histórico), ${ }^{3}$ e a integrar-se no sistema, ou num outro caminho, e partir para posições mais radicais, fora dos quadros consentidos.

Esses dois caminhos serão trilhados pelos dois trabalhos mais influentes que a escola de sociologia de São Paulo produziu antes de ela própria começar a se dividir. Apesar de seu método científico, serão significativamente dois grandes ensaios, Dependência e desenvolvimento na América Latina, de Fernando Henrique Cardoso \& Enzo Faletto (1970), e A revolução burguesa, de Florestan Fernandes (1974), que apontarão para as duas direções, para os dois grandes ramos da teoria da dependência latino-americana.

Esse fato não estava ainda claro para Carlos Guilherme Mota quando escreveu seu livro. Para ele, como para An- tonio Candido, a dependência era um problema cultural - e, no entanto, ela havia se transformado em uma visão de mundo, em uma ideologia chamada de "teoria". A teoria da dependência, que discuti em um ensaio relativamente recente (Bresser-Pereira, 2005), tem como características centrais sua rejeição da ideia à revolução burguesa e à simples possibilidade da existência de uma burguesia nacional que lideraria essa revolução. Não seria, portanto, legítimo nos países dependentes pensar em uma nação nos termos clássicos do capitalismo. Tem, entretanto, duas vertentes: uma radical e a outra "associada". Sua versão original é radical. Segundo seu fundador, André Gunder Frank (1966), e seu principal representante latino-americano, Ruy Mauro Marini (1969, 1973), a solução para a dependência seria a revolução socialista, já que os povos subdesenvolvidos são vítimas de uma exploração em dois estágios (do império central e das elites locais), vítimas, portanto, de uma “superexploração imperialista”. Essa é a posição que será também adotada por Florestan Fernandes quando, com $A$ revolução burguesa, ele completa sua transição pessoal para a esquerda.

A alternativa à tese da superexploração será a teoria da "dependência associada" de Fernando Henrique Cardoso \& Enzo Faletto (1970), que reconhece a dependência e compartilha seu pressuposto (não existe burguesia nacional), mas, como é formulada no momento do "milagre econômico" brasileiro (19681973), não considera essa falta incompatível com o desenvolvimento econômico. Pelo contrário, e de forma paradoxal, já que muita gente a compreendeu como uma forma nova de criticar o imperialismo implicando a burguesia mais expli- 
citamente no processo de dominação, a versão associada da teoria da dependência não considera os países ricos como imperialistas, mas, sim, como aliados que podem contribuir para o desenvolvimento econômico da periferia mediante a "necessária" poupança externa (déficit em conta corrente) financiada pelos investimentos diretos de suas empresas multinacionais. Esse caráter contraditório da teoria da dependência associada a torna ambígua, o que facilitou que se tornasse um grande êxito nos Estados Unidos ao tempo em que se tornava dominante na América Latina. Não se percebia então que ela não atacava apenas o nacional-desenvolvimentismo do Iseb, mas também o da Cepal dos anos 1950 - o momento do pensamento latino-americano em que as grandes figuras são Raul Prebisch e Celso Furtado e a "relação centro-periferia" é um eufemismo para indicar a relação clássica império-colônia.

Para se tornar hegemônica, entretanto, a teoria da dependência associada não podia simplesmente se conciliar de forma ambígua com o imperialismo. Ela deveria ter uma proposta positiva e de esquerda para a América Latina. Essa proposta foi dupla: a luta pela democracia e pela justiça social. Os regimes autoritários haviam-se imposto aos países latino-americanos no quadro da guerra fria, embora nos países mais avançados da região, como o Brasil, o México, a Argentina, o Chile, a Costa Rica e o Uruguai, já existissem as condições necessárias para a instalação de um regime democrático consolidado. Por sua vez, a distribuição de renda sempre fora muito desigual na região, de forma que lutar por uma maior equidade era um projeto não apenas dos pobres e dos trabalhadores, mas de amplos setores das classes médias.

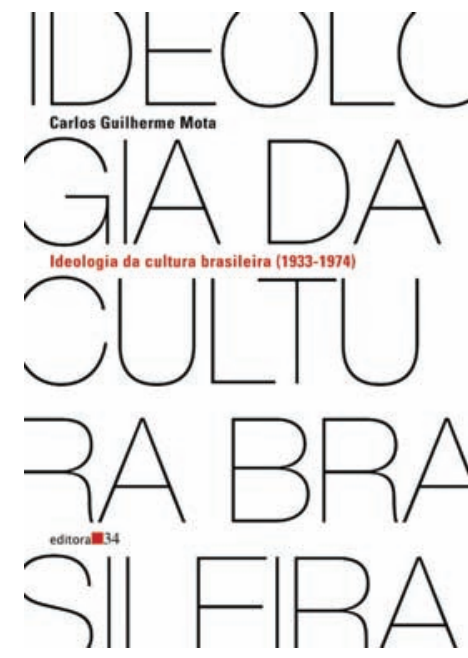

MOTA, Carlos Guilherme. Ideologia da cultura brasileira (1933-1974).

2.ed. São Paulo: Editora 34, 2008. 424p.

Embora o que acabo de expor não estivesse perfeitamente claro para Carlos Guilherme porque ele vivia o momento, o grande tema de Ideologia da cultura brasileira é a transição ideológica e intelectual que ocorre no Brasil em torno do golpe militar de 1964. Essa transição começara antes, durante os anos 1950, quando ocorre uma série de "fatos históricos novos" que inviabilizaram o pacto popular-nacional de Getúlio Vargas e, no quadro de um vácuo de poder, tornaram possível a eleição de Jânio em 1960. Analisei esses fatos novos em um trabalho de 1963 e na primeira edição de $D e$ senvolvimento e crise no Brasil (BresserPereira, 1968, cap.4). ${ }^{4}$ Esses fatos, entre os quais os mais importantes foram a Revolução Cubana em 1959 e a superação do conflito entre agricultura e indústria no Brasil em razão da consolidação desta última, enquanto a primeira deixava de protestar contra o confisco cambial pela queda dos preços internacionais do café, tornaram então superada a aliança da 


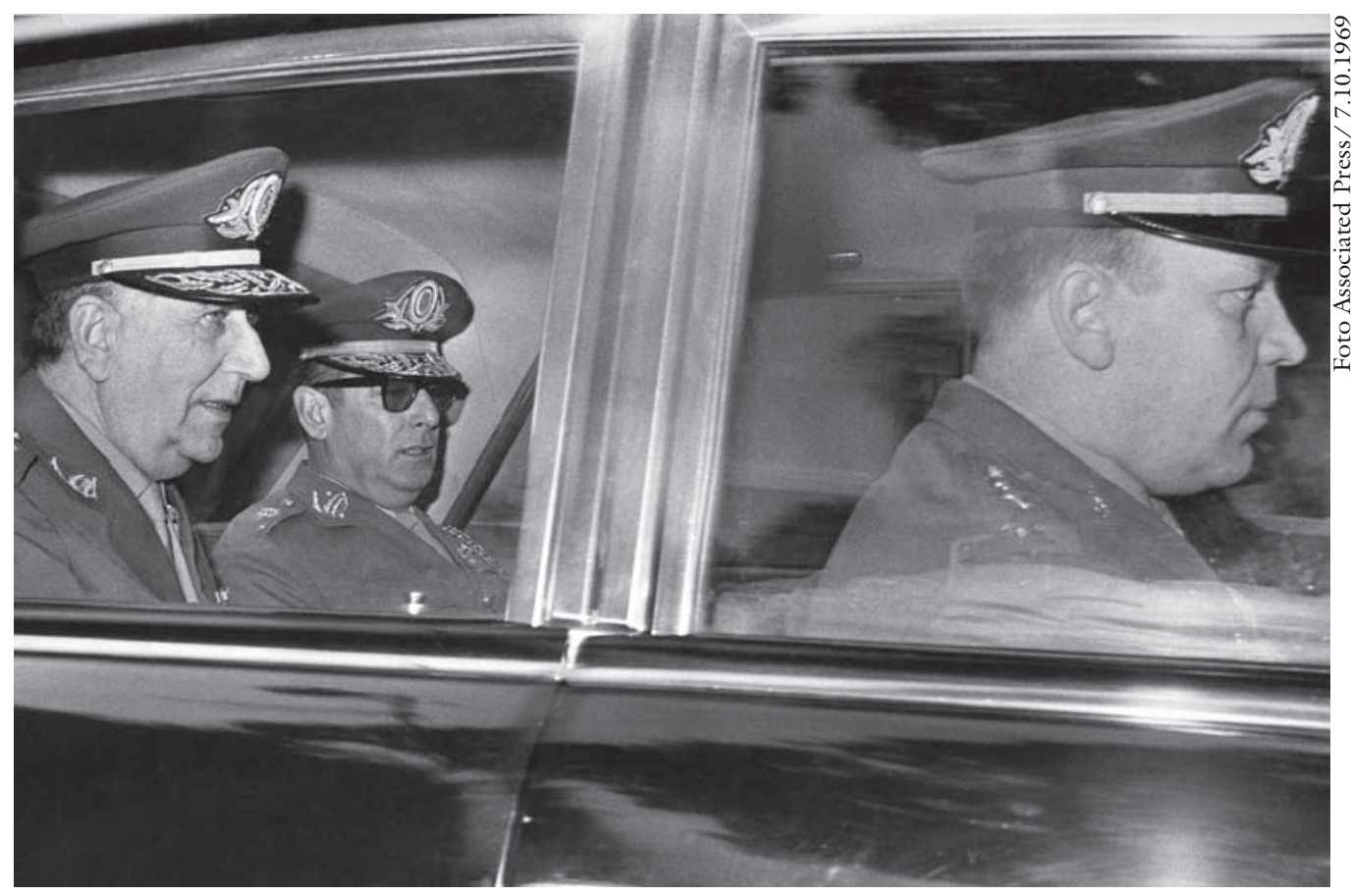

O general Emilio Garrastazu Médici (primeiro à esquerda) deixa o Palácio das Laranjeiras, no Rio de Janeiro, depois de ser indicado como novo presidente da República do Brasil, em 1969.

burguesia nacional com as esquerdas ou com os trabalhadores. Assim, a interpretação nacional-burguesa do Iseb (uma interpretação moderada) se esvaziava em consequência da crise econômica e política de 1960-1964, enquanto cresciam as duas interpretações relacionadas com a teoria da dependência: a da superexploração e da dependência associada, que também chamei de interpretação funcional capitalista porque, para os intelectuais do Cebrap, ${ }^{5}$ como não podia haver revolução capitalista e nacional na periferia, não havia também dualidade entre o pré-capitalismo ou o capitalismo mercantil e o capitalismo industrial, só havia capitalismo, e tudo era funcional a ele. ${ }^{6}$

O golpe de Estado de 1964, ao ser comandado pelos militares e pela burguesia industrial (os dois grupos nacionalistas que, com o restante da burocracia pública, haviam liderado o pacto popu- lar-nacional e a interpretação nacionalburguesa), assinalava o final não apenas desse pacto, mas de todo um ciclo da sociedade brasileira - o ciclo que chamei recentemente de Ciclo Nação e Desenvolvimento, que começa com Silvio Romero na última década do século XIX e termina com o último grande livro do ciclo, Formação econômica do Brasil, de Celso Furtado (1959). De acordo com essa perspectiva (Bresser-Pereira, 2007, p.33-7), o Estado é sempre a expressão da sociedade, de forma que os ciclos ideológicos da sociedade são sempre seguidos por modificações no pacto político dominante; entretanto, isso acontece com uma defasagem, de forma que o pacto político pode sobreviver por algum tempo enquanto a sociedade está mudando. Nos anos que se seguem a 1964, portanto, no plano do Estado o pacto nacional-desenvolvimentista fora restabelecido pelos militares e empresá- 
rios sem a participação dos trabalhadores e da esquerda, mas como o ciclo da sociedade se esgotara, abria-se espaço para um novo ciclo da sociedade brasileira: o Ciclo Democracia e Justiça Social.

O novo ciclo da sociedade, apoiado na teoria da dependência associada e nos trabalhos do Cebrap, gradualmente se torna hegemônico, porque, nos anos 1970, em pleno milagre econômico, o desenvolvimento econômico havia deixado de ser prioridade para a sociedade civil. E também porque se tornava cada vez mais claro que os tempos do autoritarismo haviam passado para o Brasil - que sua sociedade já complexa e relativamente desenvolvida, contando com uma grande classe média burguesa e outra profissional ou tecnoburocrática, e com uma maior ainda classe trabalhadora crescentemente organizada, não podia mais ser submetida a um regime autoritário. O golpe de 1964, completado pelo Ato Institucional n.5 de 1968, já não fazia sentido. Ele fizera algum sentido para seus autores em razão da Revolução Cubana e da radicalização da esquerda e da direita que se segue, mas agora nem mesmo para eles podia ser justificado.

Quando lemos hoje Ideologia da cultura brasileira (1933-1974), mais de 35 anos transcorridos do momento em que o livro foi escrito, parece-me importante que o leiamos a partir dessa perspectiva. O centro do belo livro de Carlos Guilherme está nos anos que se seguem a 1964, está na transição do nacionalismo do Iseb e da Cepal para a dependência agora considerada inevitável pela teoria da dependência associada e da escola de sociologia de São Paulo; está na mudança de ênfase do desenvolvimento econômico para a democracia e a justiça social.
Em meados dos anos 1970, quando o livro termina de contar a história que se propôs contar, a sociedade civil brasileira começava a se organizar para, afinal, estabelecer o sufrágio universal e a democracia no Brasil. A transição democrática que começa em 1977, com a reação da sociedade civil ao "pacote de abril" do presidente Ernesto Geisel, terminará no final de 1984 com o estabelecimento de um governo civil, e com a Constituição de 1988 que, afinal, estabelecerá o sufrágio universal. O período de 1977 a 1985 é o grande momento dos intelectuais brasileiros. Desde a crise da dívida externa de 1980, porém, o desenvolvimento econômico, que se pensara garantido nos anos 1970, havia paralisado, porque o Brasil não se revelou capaz de enfrentar novos desafios, pois a nação se enfraquecera e não mais contava com o nacional-desenvolvimentismo. Ora, na era da globalização, um país sem uma estratégia nacional de desenvolvimento não tem condições para enfrentar a competição entre os Estados-nação que caracteriza essa etapa do capitalismo. Por isso, desde os anos 1970, depois de termos visto boa parte dos intelectuais de esquerda - muitos identificados com a teoria da dependência associada - perderem uma visão abrangente do Brasil, estamos vendo nos anos 2000 esgotarse o Ciclo Democracia e Justiça Social, porque esse, desde 1980, deixou de ser acompanhado, se não financiado, pelo desenvolvimento econômico. Estamos agora em um momento de síntese entre os dois ciclos, mas para que essa síntese realmente se realize será preciso pensar e repensar a formação e o desenvolvimento da cultura brasileira - dois temas para os quais este livro oferece uma contribuição inestimável. 
Notas

l A nova edição afirma ser a "terceira", mas a "segunda" edição foi apenas uma das muitas reimpressões. Esta é uma nova edição não apenas porque tem uma apresentação adicional, mas porque é publicada por nova editora. É pena que a Editora 34 , seguindo uma prática equivocada de outras grandes editoras brasileiras, não tenha mantido a mesma paginação da edição original, colocando a nova apresentação em números romanos, como fazem as grandes editoras americanas e inglesas.

2 Essa frase faz parte de entrevista que Ruth Cardoso deu à revista Visão, 11 de março de 1974, p.155.

3 Mota refere-se aqui a Karl Mannheim o grande sociólogo da sociologia do conhecimento.

4 Nas demais edições esse capítulo não foi alterado.

5 Cebrap é a sigla para Centro Brasileiro de Análise e Planejamento. Na verdade, foi um centro de estudos e de debates de oposição ao regime autoritário liderado por Fernando Henrique Cardoso depois que ele e mais um grupo de intelectuais da escola foram aposentados compulsoriamente em 1969, entre as primeiras medidas após o Ato Institucional n.5. Teve grande influência nos anos 1970.

6 Discuti as interpretações do Brasil no trabalho "Seis interpretações sobre o Brasil" (Bresser-Pereira, 1982). Nesse trabalho vejo duas interpretações antes de 1964: a da vocação agrária e a nacional burguesa - e quatro depois do golpe: a autoritáriomodernizante, a da superexploração capitalista, a funcional-capitalista ressentida (que hoje eu prefiro chamar de "da dependência associada") e a da nova dependência à qual eu me identificava porque reconhecia a dependência das elites latino-americanas, e, em consequência, seu caráter essencialmente ambíguo, mas não excluía a possibilidade de uma burguesia nacional.
Referências bibliográficas

BRESSER-PEREIRA, L. C. O empresário industrial e a Revolução Brasileira. Revista de Administração de Empresas, v.2, n.8, p.11-27, 1963.

Desenvolvimento e crise no Brasil:

1930-1967. Rio de Janeiro: Zahar Editores, 1968.

Seis interpretações sobre o Brasil. Dados, v.25, n.3, p.269-306, 1982.

Do Iseb e da Cepal à teoria da dependência. In: TOLEDO, C. N. de. (Org.) Intelectuais e politica no Brasil: a experiência do Iseb. Rio de Janeiro: Revan, 2005. p.201-32.

Macroeconomia da estagnação. São Paulo: Editora 34, 2007.

CANDIDO, A. Literatura e subdesenvolvimento. Argumento, v.1, n.1, p.7-24, 1973.

CARDOSO, F. H.; FALETTO, E. Dependência e desenvolvimento na América Latina. São Paulo: Difusão Européia do Livro, 1970.

FAORO, R. Os donos do poder. Porto Alegre: Globo, 1957.

FERNANDES, F. A revolução burguesa. Rio de Janeiro: Zahar Editores, 1974.

FRANK, A. G. The development of underdevelopment. Monthly Review, v.18, n.4, 1966.

FURTADO, Celso. Formação econômica do Brasil. Rio de Janeiro: Fundo de Cultura, 1959.

MARINI, R. M. Subdesarrollo y revolución. México: Siglo XXI, 1969.

Dialética da dependência. Coimbra: Centelha, 1976.

PRADO JUNIOR, C. Evolução politica do Brasil e outros estudos. 2.ed. São Paulo: Brasiliense, 1957. A revolução brasileira. São Paulo: Brasiliense, 1966. 
SCHWARZ, R. As idéias fora do lugar. Estudos Cebrap, v.3, p.149-62, 1973. [Republicado em Ao vencedor as batatas. São Paulo: Livraria Duas Cidades, 1981].

SIMONSEN, R. História econômica do Brasil: 1500-1820. São Paulo: Cia. Editora Nacional, 1937.

Luiz Carlos Bresser-Pereira é professor emérito da Fundação Getúlio Vargas de São Paulo. @-1cbresser@uol.com.br 